Janssen, Lilly, Novartis, Roche, UCB, Matthew J Loza Shareholder of: Johnson \& Johnson, Employee of: Janssen Research \& Development, LLC, Arumugam Palanichamy Shareholder of: Johnson \& Johnson, Employee of: Janssen Research \& Development, LLC, Oliver FitzGerald Speakers bureau: AbbVie, Amgen, BMS, Celgene, Janssen, Lilly, Novartis, Consultant of: AbbVie, Amgen, BMS, Celgene, Janssen, Lilly, Novartis, Christopher T. Ritchlin Speakers bureau: AbbVie, Amgen, Gilead, Janssen, Lilly, Novartis, Pfizer, UCB, Consultant of: AbbVie, Amgen, Gilead, Janssen, Lilly, Novartis, Pfizer, UCB, Frederic Baribaud Shareholder of: Johnson \& Johnson, Employee of: Janssen Research \& Development, LLC, Kristen Sweet Shareholder of: Johnson \& Johnson, Employee of: Janssen Research \& Development, LLC. DOI: 10.1136/annrheumdis-2021-eular.779

\section{POS1037 CORRELATION BETWEEN SKIN INVOLVEMENT, JOINT INVOLVEMENT AND ENTHESITIS IN PATIENTS WITH ACTIVE PSORIATIC ARTHRITIS: POST-HOC ANALYSIS OF EQUATOR/EQUATOR2}

P. J. Mease ${ }^{1,2}$, L. C. Coates ${ }^{3}$, F. Van den Bosch ${ }^{4}$, D. D. Gladman ${ }^{5}$, L. Gheyle ${ }^{6}$, M. Trivedi ${ }^{7}$, M. Alani ${ }^{7,8}$, E. Vetters ${ }^{9}$, F. O. Le Brun ${ }^{10}$, R. Besuyen ${ }^{11}$, P. Helliwell ${ }^{12}$ ${ }^{1}$ Swedish Medical Center, Rheumatology Clinical Research Division, Seattle, United States of America; ${ }^{2}$ University of Washington, School of Medicine, Seattle, United States of America; ${ }^{3}$ University of Oxford, Nuffield Department of Orthopaedics, Rheumatology and Musculoskeletal Sciences, Oxford, United Kingdom; ${ }^{4}$ Ghent University, VIB Center for Inflammation Research, Ghent, Belgium; ${ }^{5}$ Schroeder Arthritis Institute, Krembil Research Institute, University Health Network, Toronto, Canada; ${ }^{6}$ Galapagos NV, Clinical Research, Mechelen, Belgium; ${ }^{7}$ Gilead Sciences, Inc., Clinical Research, Foster City, United States of America; ${ }^{8}$ University of Washington, Rheumatology Department, Seattle, United States of America; ${ }^{9}$ Galapagos NV, Biometrics, Mechelen, Belgium; ${ }^{10}$ Galapagos $\mathrm{GmbH}$, Biometrics, Basel, Switzerland; ${ }^{11}$ Galapagos BV, Clinical Research, Leiden, Netherlands; ${ }^{12}$ University of Leeds, School of Medicine, Leeds, United Kingdom

Background: Psoriatic arthritis (PSA) is a heterogeneous, inflammatory disease involving multiple clinical domains including arthritis/synovitis, enthesitis, dactylitis, spondylitis and psoriasis. Effects on each domain should be assessed to determine the overall quality of treatment. Filgotinib (FIL) is a novel preferentia Janus kinase 1 inhibitor that is in development for inflammatory conditions including PSA. EQUATOR (NCT03101670) was a 16-week, Phase 2, double-blind, randomised, placebo (PBO)-controlled trial of FIL for patients with active PsA. ${ }^{1}$ EQUATOR2 (NCT03320876) is an open-label extension (OLE) of the study.

Objectives: This post-hoc analysis of EQUATOR and EQUATOR2 assessed the patient-level correlation between changes over time in the three PsA clinical disease domains of skin, joint and enthesitis in patients treated with FIL.

Methods: In EQUATOR, patients with active moderate-to-severe PsA ( $\geq 5$ swollen joints and $\geq 5$ tender joints, fulfilling Classification for PsA criteria) were randomised $1: 1$ to receive oral FIL $200 \mathrm{mg}$ or PBO once daily (QD) for 16 weeks. At Week 16, patients could continue into the 304-week OLE, with all patients receiving FIL $200 \mathrm{mg}$ QD regardless of previous treatment in EQUATOR. This post-hoc analysis was limited to patients with skin involvement ( $\geq 3 \%$ body surface area), joint involvement and enthesitis at baseline, with changes from baseline in the three domains assessed using the Psoriasis Area and Severity Index (PASI), swollen/tender joint count (S/TJC), and the Leeds Enthesitis Index (LEI) and Spondyloarthritis Research Consortium of Canada (SPARCC) index, respectively. Analyses that used LEI as the enthesitis index to assess change from baseline included patients with LEI score $\geq 1$ at baseline; those using SPARCC included patients with SPARCC score $\geq 1$ at baseline.

Results: The EQUATOR study enrolled 131 patients and 122 patients continued into the EQUATOR2 OLE. Of the 131 patients enrolled in EQUATOR, 49 and 56 patients had PsA involving all three domains at core study baseline when enthesitis was assessed using LEI and SPARCC index, respectively. Pooled data for all patients receiving FIL during the OLE indicate that improvements from baseline in the clinical domains continued with long-term treatment, with 22/42 $(52 \%)$ and $23 / 38(61 \%)$ patients having both SJC66 and LEI resolution at Weeks 52 and 100 , respectively. For the 22 patients with both SJC and LEI resolution at Week 52, the mean percent change from baseline for PASI was $-64 \%$; for the 23 patients with both SJC and LEI resolution at Week 100, the mean percent change from baseline for PASI was $-60 \%$. The Figure 1 shows correlation between SJC, LEI and PASI at Week 100. A relationship between the three clinical domains was observed at the individual level; within a single patient, an improvement in one domain was generally followed by improvements in the other two domains. With regard to the sequence in which changes were observed, joints improved first, followed by improvements in the skin and enthesitis. There were no notable differences between changes in LEI and SPARCC enthesitis index in terms of their correlation with improvements in joint and skin involvement. Similarly, there were no notable differences in correlation between the three domains when joints were assessed using TJC rather than SJC.

Conclusion: Patients with improvements in skin, joints or enthesitis following treatment with FIL generally also had improvements in the other clinical domains of PsA. The joints were found to be the first of the three domains to improve.

\section{REFERENCES:}

[1] Mease $P$ et al. Lancet 2018;392:2367-77

Figure: Correlation between SJC, LEI and PASI at Week 100 of the OLE

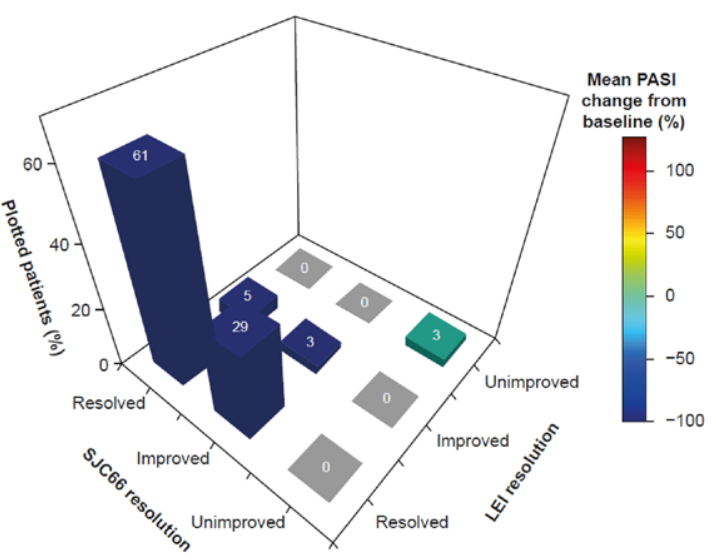

Plot shows observed cases. Number of plotted patients: 38 out of 49 patients with involvement in all three
Resolved - $-100 \%$ percent change from baseline; Improved: $-100 \%<$ percent change from baseline $<0 \%$;

Unimproved. $0 \% \leq$ percent change from baseline.
Patients were on placebo or filigotinib $(200 \mathrm{mg})$ during the core study (initial 16 weeks)

Patients were on placebo or filgotinib (200 mg) during the core study (initial 16 weeks).
LEI, Leeds Enthesitis Index; OLE, open-label extension; PASI, Psoriasis Area and Severity Index; SJC(66), (66-)swollen joint count.

Acknowledgements: EQUATOR and EQUATOR2 were sponsored by Galapagos NV (Mechelen, Belgium) and co-funded by Galapagos NV and Gilead Sciences, Inc (Foster City, CA, USA). Medical writing/editorial support was provided by Debbie Sherwood, BSc, CMPP (Aspire Scientific, Bollington, UK), funded by Galapagos NV. Disclosure of Interests: Philip J Mease Speakers bureau: AbbVie, Amgen, Eli Lilly, Janssen, Novartis, Pfizer, and UCB, Consultant of: AbbVie, Amgen, Boehringer Ingelheim, Bristol-Myers Squibb, Eli Lilly, Galapagos, Gilead Sciences, GlaxoSmithKline, Janssen, Novartis, Pfizer, SUN and UCB, Grant/research support from:AbbVie, Amgen, Bristol-Myers Squibb, Celgene, Eli Lilly, Galapagos, Gilead Sciences, Janssen, Novartis, Pfizer, SUN and UCB, Laura C Coates Speakers bureau: AbbVie, Amgen, Biogen, Celgene, Eli Lilly, Gilead, Janssen, Medac, Novartis, Pfizer and UCB, Consultant of AbbVie, Amgen, Boehringer Ingelheim, Bristol-Myers Squibb, Celgene, Eli Lilly, Gilead, Janssen, Novartis, Pfizer and UCB, Grant/research support from: AbbVie, Amgen, Celgene, Eli Lilly, Novartis, and Pfizer, Filip van den Bosch Consultant of: AbbVie, Celgene, Eli Lilly, Galapagos, Gilead, Janssen, Merck, Novartis, Pfizer, and UCB, Grant/research support from: AbbVie, Merck and UCB, Dafna D Gladman Consultant of: AbbVie, Amgen, Bristol-Myers Squibb, Celgene, Eli Lilly, Galapagos, Gilead, Janssen, Novartis, Pfizer, and UCB, Grant/research support from: AbbVie, Amgen, Celgene, Eli Lilly, Janssen, Novartis, Pfizer and UCB, Lien Gheyle Shareholder of: Galapagos, Employee of: Galapagos, Mona Trivedi Shareholder of: Gilead Sciences, Amgen, Employee of: Gilead Sciences, Muhsen Alani Shareholder of: Gilead Sciences, Employee of: Gilead Sciences, Eline Vetters Employee of: Galapagos, Franck Olivier Le Brun Shareholder of: Galapagos, Employee of: Galapagos, Robin Besuyen Shareholder of: Galapagos, Employee of: Galapagos, Philip Helliwell Speakers bureau: Janssen and Novartis, Paid instructor for: Pfizer, Consultant of: Eli Lilly.

DOI: 10.1136/annrheumdis-2021-eular.883

\section{POS1038 THE EFFECT OF FILGOTINIB ON ENTHESITIS: 100-WEEK DATA FROM AN OPEN-LABEL EXTENSION STUDY IN PATIENTS WITH ACTIVE PSORIATIC ARTHRITIS}

P. Helliwell ${ }^{1}$, L. C. Coates ${ }^{2}$, F. Van den Bosch ${ }^{3}$, D. D. Gladman ${ }^{4}$, L. Gheyle ${ }^{5}$, M. Trivedi ${ }^{6}$, M. Alani ${ }^{6,7}$, F. O. Le Brun ${ }^{8}$, R. Besuyen ${ }^{9}$, P. J. Mease ${ }^{10,11}{ }^{1}{ }^{1}$ University of Leeds, School of Medicine, Leeds, United Kingdom; ${ }^{2}$ University of Oxford, Nuffield Department of Orthopaedics, Rheumatology and Musculoskeletal Sciences, Oxford, United Kingdom; ${ }^{3}$ Ghent University, VIB Center for Inflammation Research, Ghent, Belgium; ${ }^{4}$ Schroeder Arthritis Institute, Krembil Research Institute, University Health Network, Toronto, Canada; ${ }^{5}$ Galapagos NV, Clinical Research, Mechelen, Belgium; ${ }^{6}$ Gilead Sciences, Inc., Clinical Research, Foster City, United States of America; ${ }^{7}$ University of Washington, Rheumatology Department, Seattle, United States of America; ${ }^{8}$ Galapagos GmbH, Biometrics, Basel, Switzerland; ${ }^{9}$ Galapagos BV, Clinical Research, Leiden, Netherlands; ${ }^{10}$ Swedish Medical Center, Rheumatology Clinical Research Division, Seattle, United States of America; ${ }^{11}$ University of Washington, School of Medicine, Seattle, United States of America

Background: Filgotinib (FIL), a novel preferential Janus kinase 1 inhibitor, was assessed in patients with active psoriatic arthritis (PsA) in the 16-week, Phase 2 EQUATOR trial (NCT03101670). ${ }^{1}$ EQUATOR2 (NCT03320876) is the open-label extension (OLE). As previously reported, an interim analysis of the OLE showed that the majority of patients had clinical resolution of enthesitis by Week $52 .^{2}$ 